\title{
Moderation of directors' education on board busyness-firm efficiency
}

\begin{abstract}
Purpose: The purpose of this paper is to enhance the understanding of the long-debated impact of board busyness within a new framework of firm efficiency in the selected developed and developing Asia-Pacific countries, by assessing the moderation of directors' education towards the relationship between board busyness and firm efficiency. The extant literature on board busyness demonstrates to a lack of clarification of the relationship between board busyness and firm efficiency. Design/methodology/approach:The sample for this paper comprises a panel data of 800 firms in a cross-country context of the selected developed and developing AsiaPacific countries during the recent period of 2009-2015. This paper performs a non-parametric Data Envelopment Analysis to measure firm efficiency and panel regression analysis to examine the moderation of directors' education. Findings: This paper provides support for the busyness hypothesis by documenting that the busy boards are likely to reduce firm efficiency. Moreover, this paper renders support to the upper-echelons theory by demonstrating that the impact of board busyness on firm efficiency is likely to turn positive in the presence of directors' education. Practical implication: This paper highlights practical implication for managers especially in the Asia-Pacific region who seek to enhance firm efficiency, which is essential for firms in attaining the primary goal of profit maximization. Originality/value: This paper builds on the extant literature by providing a contemporary research path regarding the moderation of directors' education to explain the long-debated impact of board busyness within a new framework of firm efficiency, based on a recent and significant sample of Asia-Pacific countries.
\end{abstract}

Keyword: Directors' education; Moderation; Board busyness; Firm efficiency; Asia-Pasific countries; Panel regression analysis 
